\title{
Hysterosalpingo-foam sonography (HyFoSy) using two different balloon catheters: a randomized trial
}

\author{
Dominique Van Schoubroeck • Thierry Van den Bosch • \\ Lieveke Ameye • Thomas D'Hooghe • Dirk Timmerman
}

Received: 31 July 2014 / Accepted: 14 October 2014 /Published online: 28 October 2014

(C) Springer-Verlag Berlin Heidelberg 2014

\begin{abstract}
The purposes of this study were to evaluate and compare the technical feasibility and the patients' pain during hysterosalpingo-foam sonography (HyFoSy) using two different 2-mm balloon catheters. Randomized trial in 46 consecutive women referred for tubal patency testing by HyFoSy at the Leuven University Hospital. Six women refused to participate. Forty women were randomized and blinded as to the catheter used. The patients underwent first a transvaginal ultrasound examination to assess the uterus and the ovaries and to exclude the hydrosalpinx, and subsequently, a HyFoSy was performed using an uVue catheter (Cook Medical, Bloomington, IN, USA) or a pediatric Foley's catheter with stylet (Pediatric Folysil, Coloplast A/S; Humlebaek, Denmark) according to randomization. If the catheter could not be inserted smoothly into the uterine cavity at first attempt, transabdominal ultrasound guidance was performed. After the procedure, the patients were asked to fill in a questionnaire including a visual analog scale (VAS) score for the pain at initial ultrasound examination $\left(\mathrm{VAS}_{\mathrm{US}}\right)$, used as baseline score, and at HyFoSy $\left(\mathrm{VAS}_{\mathrm{HyFoSy}}\right)$. The pain related to the HyFoSy procedure was reported as $\left(\mathrm{VAS}_{\mathrm{HyFoSy}}-\mathrm{VAS}_{\mathrm{US}}\right)$ / $\mathrm{VAS}_{\mathrm{US}}$. Catheter insertion failed in one patient of the uVue group (5\% failure rate) and in none of the Foley group. Ultrasound guidance during catheter insertion was performed in $68 \%$ of the uVue group and $20 \%$ of the Foley group. The median ratio $\left(\mathrm{VAS}_{\mathrm{HyFoSy}}-\mathrm{VAS}_{\mathrm{US}}\right) / \mathrm{VAS}_{\mathrm{US}}$ for the uVue and the Foley group was 1.82 and 0.54 , respectively $(p=0.005)$. A pediatric Foley catheter was easier to insert as compared to an uVue catheter, and HyFoSy using a pediatric Foley catheter was reported by the women to be the least painful.
\end{abstract}

D. Van Schoubroeck $(\bowtie) \cdot$ T. Van den Bosch • L. Ameye • T. D'Hooghe $\cdot$ D. Timmerman

KU Leuven Department of Development and Regeneration, University Hospital Leuven, Herestraat 49, 3000 Leuven, Belgium e-mail: Dominique.vanschoubroeck@uzleuven.be
Keywords Ultrasonography $\cdot$ Infertility $\cdot$ Female $\cdot$ Fallopian tube patency tests $\cdot$ Microbubbles

\section{Background}

Hysterosalpingo-contrast-sonography (HyCoSy) is as accurate as hysterosalpingography (HSG) in the evaluation of Fallopian tube patency and is to be preferred as it does not expose the patient nor the examiner to radiation [1-3]. Moreover, HyCoSy is reportedly less painful and better tolerated by the patients as compared to HSG. Hysterosalpingo-foam sonography (HyFoSy) is a novel variant of HyCoSy using gel foam, a mechanically mixing of water, gel, and air, as a positive contrast agent [4-8].

This study aims to evaluate and compare the technical feasibility and the patients' pain during HyFoSy using two different 2-mm balloon catheters.

\section{Methods}

We performed a randomized trial in 46 consecutive women referred for tubal patency testing by HyFoSy at the Leuven University Hospital. The study had been approved by the local ethics committee, and informed consent was obtained in all patients. Six women refused to participate. Forty women were randomized (Fig. 1) using a random number generator (https:// www.random.org/). The random assignments were placed in 40 numbered, opaque, and sealed envelopes. The envelope was opened after consent was given and just prior to the HyFoSy procedure. The patients were blinded as to the catheter used, but for obvious reasons, the clinician was not blinded. The patients underwent first a transvaginal ultrasound examination to assess the uterus and the ovaries and to exclude the hydrosalpinx, and immediately thereafter, a 


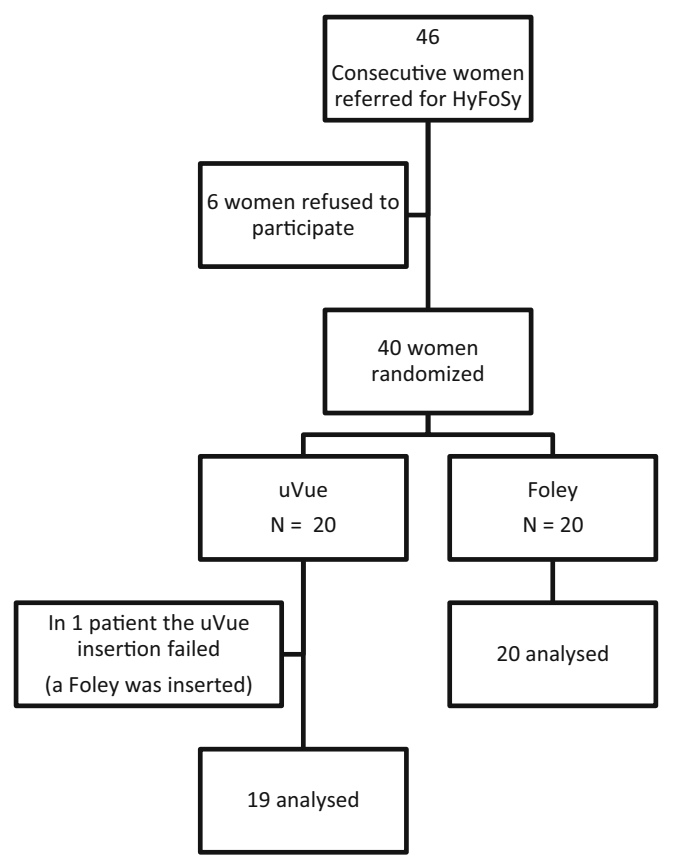

Fig. 1 Study design

HyFoSy was performed using a 2-mm uVue catheter (Cook Medical, Bloomington, IN, USA) or a 2-mm pediatric Foley's catheter with stylet (Pediatric Folysil, Coloplast A/S; Humlebaek, Denmark) according to randomization. The HyFoSy procedure was performed as outlined elsewhere [5]. An open-sided Collin speculum was inserted, the cervix disinfected with a water-based Dakin solution, and the catheter was inserted into the uterine cavity. If the catheter could not be inserted smoothly at first attempt, transabdominal ultrasound guidance was performed. Catheter insertion was performed without the use of a cervical tenaculum or a dilator. The balloon was slowly inflated with 0.5 to $1.0 \mathrm{ml}$ of saline in the lower part of the uterine cavity till the patient reported a vague pressure in the lower abdomen indicating perceptible intrauterine pressure. The speculum was removed, and the vaginal ultrasound probe was reinserted. The size of the balloon was measured in three perpendicular diameters, and

Table 1 Patients' characteristics

\begin{tabular}{lll}
\hline & $\mathrm{uVue}(n=19)^{\mathrm{a}}$ & Foley $(n=20)$ \\
\hline Mean age & 31 & 29 \\
Primary subfertility & 13 & 12 \\
Secondary subfertility & 6 & 8 \\
$P \geq 1$ & 4 & 5 \\
Unilateral block at HyFoSy & 1 & 3 \\
Bilateral block at HyFoSy & 1 & 0
\end{tabular}

$P$ parity (all nine cases had a parity of 1 )

a In one patient randomized in the "uVue" arm, a Foley was used after uVue insertion failed

Table 2 Reported pain/discomfort during HyFoSy

\begin{tabular}{llllll}
\hline & \multicolumn{2}{l}{ uVue } & & \multicolumn{2}{l}{ Foley } \\
\cline { 2 - 3 } \cline { 5 - 6 } & $N$ & & & $N$ & $\%$ \\
\hline Neutral & 1 & 5.3 & & 10.0 \\
Unpleasant & 6 & 31.6 & 8 & 40.0 \\
Painful but bearable & 7 & 36.8 & 8 & 40.0 \\
Really painful* & 5 & 26.3 & & 10.0 \\
Total & 19 & & & 20 & \\
\hline
\end{tabular}

${ }^{*} p$ value 0.24

the gel foam was slowly injected under direct ultrasound control. Tubal patency was defined as a sustained and fast forward flow of the gel foam through the entire Fallopian tube.

After the procedure, the patients were asked to fill in a questionnaire including a visual analog scale (VAS) score for the pain at initial ultrasound examination $\left(V S_{U S}\right)$, used as baseline score, and at HyFoSy $\left(\mathrm{VAS}_{\mathrm{HyFoSy}}\right)$. The pain related to the HyFoSy procedure was calculated as the median ratio $\left(\mathrm{VAS}_{\mathrm{HyFoSy}}-\mathrm{VAS}_{\mathrm{US}}\right) / \mathrm{VAS}_{\mathrm{US}}$.

The patients were asked also to describe the pain/discomfort during HyFoSy (as "neutral," "unpleasant," "painful but bearable," or "really painful") and to compare the pain/discomfort during HyFoSy with two common minor procedures (i.e., blood sampling and cervical cytology smear) as "less," "equally," or "more painful/causing discomfort."

The Fisher's exact test was used to assess the differences in categorical variables, $t$ test and Wilcoxon test were used to assess differences in continuous variables. SAS 9.4 (SAS Institute Inc., Cary, NC, USA) was used for the statistical analyses.

Table 3 Compared to blood sampling

${ }^{*} p$ value 0.48

Table 4 Compared to cervical cytology smear

* $p$ value 0.33

${ }^{\text {a }}$ One patient randomized to the Foley arm did not answer this question

\begin{tabular}{llllll}
\hline & \multicolumn{2}{l}{$\mathrm{uVue}$} & & \multicolumn{2}{l}{ Foley } \\
\cline { 2 - 3 } \cline { 5 - 6 } & $N$ & $\%$ & & $N$ & $\%$ \\
\hline Less & 0 & 0.0 & 2 & 10.0 \\
Equal & 4 & 21.1 & 5 & 25.0 \\
More* & 15 & 78.9 & 13 & 65.0 \\
Total & 19 & & & 20 & \\
\hline
\end{tabular}

\begin{tabular}{llllll}
\hline & \multicolumn{2}{l}{ uVue } & & \multicolumn{2}{l}{ Foley } \\
\cline { 2 - 3 } \cline { 5 - 6 } & $N$ & $\%$ & & $N^{\mathrm{a}}$ & $\%$ \\
\hline Less & 1 & 5.3 & & 2 & 10.5 \\
Equal & 5 & 26.3 & 7 & 24.1 \\
More* & 13 & 68.4 & & 10 & 52.6 \\
Total & 19 & & & 19 & \\
\hline
\end{tabular}


Fig. 2 Pain related to the HyFoSy procedure; for each patient, the reported pain during ultrasound examination $\left(\mathrm{VAS}_{\mathrm{US}}\right)$ and during the HyFoSy procedure $\left(\mathrm{VAS}_{\mathrm{HyFoSy}}\right)$ is presented
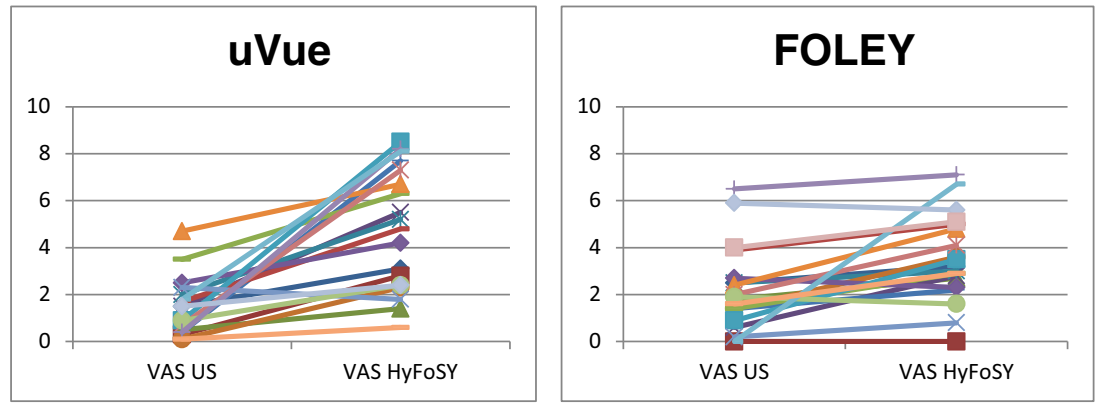

\section{Findings}

The patients' characteristics (age, parity, primary/secondary subfertility) and tubal patency for both subgroups were comparable (Table 1).

Catheter insertion failed in one patient of the $\mathrm{uVue}$ group ( $5 \%$ failure rate) and in none of the Foley group. In the patient with failed uVue catheter insertion, a Foley was inserted successfully during the same session. Ultrasound guidance for catheter insertion was performed in $68 \%$ of the uVue group and $20 \%$ of the Foley group $(p=0.004)$. The mean balloon diameter in the uVue group and the Foley group was 8.7 and $9.3 \mathrm{~mm}$, respectively $(p=0.22)$. Five women $(26 \%)$ of the uVue group reported the procedure to be really painful versus two (10\%) in the Foley group $(p=0.24)$ (Table 2).

In the uVue group and in the Foley group, 79 and $65 \%$, respectively, found HyFoSy to be more painful than blood sampling ( $p=0.48$ ) (Table 3), and 68 and $53 \%$, respectively, found $\mathrm{HyFoSy}$ more painful than a cervical cytology smear $(p=0.33)$ (Table 4).

The median $\mathrm{VAS}_{\mathrm{US}}$ in the uVue and in the Foley group was $1.5(0.1-4.7)$ and $1.9(0-6.5)$, respectively $(p=0.14)$, while the median $\mathrm{VAS}_{\mathrm{HyFoSy}}$ was $4.8(0.6-8.5)$ and $3.5(0-7.1)$, respectively $(p=0.10)$. The median ratio $\left(\mathrm{VAS}_{\mathrm{HyFoSy}}-\mathrm{VAS}_{\mathrm{US}}\right) /$ $\mathrm{VAS}_{\mathrm{US}}$ for the uVue and the Foley group was 1.82 and 0.54 , respectively ( $p=0.005$ ) (Fig. 2).

\section{Conclusions}

A 2-mm pediatric Foley catheter was easier to insert compared to an uVue catheter, and HyFoSy using a pediatric Foley catheter was reported by the women to be the least painful too.

The strength of this study is its strict randomized design, the blinding of the patients, and the fact that the study was performed by the same group in the same center, precluding an operators' bias. The weaknesses are the relatively small sample size and the impossible operators' blinding.

Both catheters have the same diameter $(2 \mathrm{~mm})$ and have a similar balloon at the tip. The main difference is the devices' rigidity, the $\mathrm{uVue}$ being stiffer. The latter has the advantage to allow insertion without the need of a swab forceps. Moreover, in case of severe ante- or retroversion of the endocervical canal, it can be bent before insertion to match/fit the shape of the canal. However, in case of a tortuous or S-shaped endocervical canal, this may prove to be a disadvantage, since the catheter will keep its pre-bended shape, the tip may "scrape" the more distal part of the canal, thus causing pain. The more difficult insertion is reflected by the significantly higher proportion of patients in the $\mathrm{uVue}$ group necessitating ultrasound guidance. Moreover, the catheter's stiffness may cause discomfort when inserting the vaginal ultrasound probe and makes the uterus more rigid during ultrasound examination. The Foley's catheter does not have the above-mentioned disadvantages, because it has a much less rigid and removable stylet to facilitate insertion, and once the stylet has been removed, the catheter is supple.

The results of our study favor the use of the Foley's catheter over the uVue catheter in term of patients' tolerance and operators' technical preference.

Conflict of interest Dominique Van Schoubroeck, Thierry Van den Bosch, Lieveke Ameye, Thomas D'Hooghe, and Dirk Timmerman declare that they have no conflict of interest.

The author's role in the study can be summarized as follows:

D. Van Schoubroeck - participation in study design, execution, analysis, manuscript drafting, and critical discussion; corresponding author

T. Van den Bosch - participation in study design, execution, analysis, manuscript drafting, and critical discussion

L. Ameye, study design and analysis

T. D'Hooghe - critical discussion

D. Timmerman — critical discussion

Informed consent All procedures followed were in accordance with the ethical standards of the responsible committee on human experimentation (institutional and national) and with the Helsinki Declaration of 1975, as revised in 2000 (5). Informed consent was obtained from all patients for being included in the study.

\section{References}

1. Campbell S, Bourne TH, Tan SL, Collins WP (1994) Hysterosalpingo contrast sonography (HyCoSy) and its future role within the investigation of infertility in Europe. Ultrasound Obstet Gynecol 4:245-253

2. Strandell A, Bourne T, Bergh C, Granberg S, Thorburn J, Hamberger L (2000) A simplified ultrasound based infertility investigation protocol 
and its implications for patient management. J Assist Reprod Genet 17: 87-92

3. Lim CP, Hasafa Z, Bhattacharya S, Maheshwari A (2011) Should a hysterosalpingogram be a first-line investigation to diagnose female tubal subfertility in the modern subfertility workup? Hum Reprod 26:967-971

4. Exalto N, Stappers C, van Raamsdonk LA, Emanuel MH (2007) Gel instillation sonohysterography: first experience with a new technique. Fertil Steril 87:152-155

5. Emanuel MH, Exalto N (2011) Hysterosalpingo-foam sonography (HyFoSy): a new technique to visualize tubal patency. Ultrasound Obstet Gynecol 37:497-499
6. Emanuel MH, van Vliet M, Weber M, Exalto N (2012) First experiences with hysterosalpingo-foam sonography (HyFoSy) for office tubal patency testing. Hum Reprod 27:114-117

7. Van Schoubroeck D, Van den Bosch T, Meuleman C, Tomassetti C, D'Hooghe T, Timmerman D (2013) The use of a new gel foam for the evaluation of tubal patency. Gynecol Obstet Investig 75: $152-156$

8. Van Schoubroeck D, Van den Bosch T, Ameye L, Boes AS, D'Hooghe T, Timmerman D (2014) Pain during Fallopian tube patency testing by hysterosalpingo-foam-sonography (HyFoSy). Ultrasound Obstet Gynecol. doi:10.1002/uog.14646 